\title{
EFFECT OF PEDOMETER BASED AEROBIC WALKING PROGRAM ON STEPS COUNT AND RESTING HEART RATE AMONG ATRIAL FIBRILLATION PATIENTS ${ }^{1}$ Mohamed Elsayed Elzeky, ${ }^{2}$ Kamelia Fouad Abd allah, ${ }^{3}$ Wafaa Ismail Sherief ,and ${ }^{4}$ Heba Abobakr M.Salama. \\ 1, 3, 4, Medical-Surgical Nursing Department, Faculty of Nursing-Mansoura University 2Medical Surgical Nursing Department, Faculty of nursing-Ain Shams University \\ E-mail of corresponding author: moh.hamed69@yahoo.com
}

\begin{abstract}
Atrial fibrillation (AF) is the most prevalent clinical arrhythmia found in clinical practice. Patients with AF have greater activity impairment which affects daily life, leading to a more sedentary lifestyle. Exercise training have various benefits for AF patients including improvements in frequency control, functional capability, activities of daily living and a lower resting pulse rate. Pedometers have recently gained recognition as a useful intervention in the promotion of physical activity (PA). Therefore, the aim of the study was to examine the effect of pedometer based aerobic walking program on steps count and resting heart rate among Patients with AF. Methods Quasi-experimental research design was carried out in outpatient cardiovascular clinic of the Specialized - Medical Hospital, at Mansoura University. Purposive sample of this study composed of 60 adult patients of both sexes who met inclusion criteria and divided alternatively into two equal groups study and experimental. Results the result shows significant improvement in step count by 2814 step \day and drop in resting heart rate by 4 beat / minute in study group after program. Conclusion positive effect of pedometer based aerobic walking program on exercise parameters of AF patients.
\end{abstract}

Key words: atrial fibrillation, pedometer self monitoring, step count goals

\section{Introduction:}

Atrial fibrillation (AF) is the most prevalent clinical arrhythmia with a global burden that has increased progressively, contributing to rising hospitalizations and substantial healthcare demands ${ }^{(1-3)}$. Rates propose an AF prevalence of about $3 \%$ in adults aged twenty years or older, with increasing prevalence in aged people and in patients with comorbidities like hypertension (HTN), heart failure (HF), coronary artery disease (CAD), valvular heart disease, obesity, diabetes mellitus (DM), or chronic kidney disease ${ }^{(4)}$.

The AF patients have greater activity impairment in comparison with non AF individuals which affect daily life, leading to a more sedentary lifestyle owing to symptoms or apprehension of exciting episodes of AF. ${ }^{(5-7)}$.

Prior researches have revealed exercise training benefits among patients with chronic AF involving enhancements in health-related QoL and a decrease in resting heart rate ${ }^{(8-10)}$. A meta-analysis regarding benefits of $\mathrm{PA}$, it produce enhancements in frequency control, lower risk of AF-recurrence following ablation, and raised QoL in all AF types $\mathrm{AF}^{(11)}$. In addition exercise training and $\mathrm{PA}$ improves the management of hypertension and diabetes, assists in weight management and improves cardiac function $^{(12)}$.

It is recommended that cardiac patients should accumulate a minimum of thirty 
min/day, five days/wk of moderate intensity PA (such as purposeful walking) practiced in bouts with a period of a minimum of ten minutes ${ }^{(13-14)}$; which is equivalent to 3,000 steps in thirty minutes daily at moderate intensity ( cadence of 100 step / minute) ${ }^{(15)}$.

Despite the numerous and substantial health benefits of being physically active for cardiac patients, the majority of studies done at Mansoura university among patients with AF, CAD and hypertension reported patient non compliance with exercise ${ }^{(16-19)}$.

Behavior change strategies that include short and long-term goal setting, combined with self-monitoring of goal progress, have been shown to be effective in increasing PA. Studies show that real-time self-monitoring of PA with the use of pedometers is an effective strategy in promoting PA ${ }^{(20-21)}$.

Pedometers have recently gained recognition as a useful intervention in the promotion of PA, they are cheap and simple to utilize, encourage monitoring and enhancement in daily PA levels, and allow for an instant, continuing assessment of daily PA goals. They need less effort and are compatible with most activities of daily life ${ }^{(22)}$.In This study we aimed to examine the effect of pedometer based aerobic walking program on steps count and resting heart rate among atrial fibrillation Patients.

\section{Subjects \& Method}

\section{Study Design:-}

Quasi-experimental research design was used in this study ${ }^{(38)}$.

\section{Study hypothesis:}

Patients who practice 12 weeks of aerobic walking program using pedometer and individualized step count goals will have significant improvement in step count and resting heart rate than those who receive routine care only.

\section{Setting:-}

This study was conducted at outpatient cardiovascular clinic in Specialized Medical Hospital, at Mansoura University.

\section{Subjects}

A purposive total sample of all $\mathrm{AF}$ adult patients admitted through a period of 6 months, from the beginning of September 2015 to the end of February 2016 at previously mentioned above setting were enrolled in the study and it comprised 60 patients. A power analysis was calculated for selected sample size using Dss research.com ${ }^{(23)}$; at confidence level $95 \%$, and it was $83 \%$.

The study patients were randomly assigned to 2 equal groups; a study group, consisting of 30 patients who received the routine hospital care and the planned pedometer based aerobic walking program, and a control group, consisting of 30 adult patients who received the routine hospital care only.

The patients were selected based on the following criteria

\section{Inclusion criteria:}

Adult patients diagnosed with $\mathrm{AF}$ since 6 months or more, willing to participate in the study, both sex, Aged from 20 to lower than 60 years old, Able to speak, read, and write or have care giver who can read and write, and Available for telephone follow-up.

Exclusion criteria:

Planning for surgical treat-ment, with diagnosed psychosis or currently undergoing anti-psychotic treatment, pulmonary disease or other co-morbid conditions that limit physical exercise, European Heart Rhythm Association (EHRA) functional class IV, and Thyroid dysfunction.

Tools:

The following tools were utilized to collect data pertinent to the study 
EFFECT OF PEDOMETER BASED AEROBIC WALKING etc...

Tool 1: Demographic characteristics
and medical information interview
sheet:

To assess, age, sex, marital status, occupation, educational level, history of disease and EHRA score.

Tool II: Aerobic walking exercise parameters sheet:

Two categories of exercise parameters were assessed in this study: step count \& pulse rate. Step count was assessed using a pedometer. Radial pulse rate was assessed using palpatory method while patient at rest and arm is supported. Mean weekly Step count was categorized as following into four levels according to Tudor locke etal ${ }^{(15)}$ : (sedentary -with only basal activity less than 2500, Sedentary-with limited activity2500 4999, low active5000-7499 and active $\geq$ 7500 Steps \day).

\section{Methods:}

Written permission to carry out the study was acquired by the researcher from responsible authorities of cardiology department of specialized Medical hospital, Mansoura University.Official permission to import 50 pedometer device model (KFJ-23D) from china was obtained from Egyptian ministry of health after reviewing model characteristics and suitability for research objectives.

Developed tools I\& II were reviewed by 7 specialists in the study area to ensure content validity and the necessary modification was done.Tools were tested for reliability by test-retest measurement and Cronbach's alpha.

The pedometer based aerobic walking program was developed by the researcher based on review of literature $\mathrm{A}$ booklet comprising the content of the program was prepared by the researcher and tested for content validity and the necessary modifications were done. It is written in plain Arabic language and supplemented by photos to help the patient's understanding of the content
Verbal clarification of the study nature and objective was done for medical and nursing staff. A total of 66 patients attended cardiology clinics in SpecializedMedical Hospital. A pilot study was performed on 6 patients to evaluate tools clarity and applicability .These patients were excluded from the study sample.

Human rights and Ethical consideration, prior to the pilot of this study, informed written consent was obtained from each participating patient prior to his /her inclusion into the study. Clarification of the nature and purpose of the study was done on the interview with each client .The investigator emphasized participation is absolutely voluntary. Anonymity, privacy, safety and confidentiality were assured the right to withdraw from the study at any time.

Once the necessary approvals granted to proceed with the proposed study, patient who met sampling criteria \& agreed to participate in the study, interviewed by the researcher to collect the necessary data and implement the program following clarification of study aim.

According to the previous mentioned study criteria. The patients were randomly allocated to 2 equal groups; one study or intervention group who will submit to pedometer based aerobic walking program, and control group who receive routine care only.Each patient (both control and study group) were interviewed individually before applying the planned pedometer based aerobic walking program in order to collect patient's baseline data using the tools of the study.

After that Pulse was assessed using palpatory method from radial artery and counted for full 1 minute and noting rhythm and volume while the patient rested for at least 15 minutes.Following that, before using pedometer, all participants finished a 20-step test to 
verify that pedometer position at the waist gave accuracy within \pm 2 of actual steps.

At the end of assessment phase, all patients finished a baseline week wearing a pedometer, covered with plaster, for seven days during all waking hours (excluding when bathing, sleeping) with instructions not to change their daily routine.Patients in the study group put on the pedometer daily for the whole study duration, while the control group just put on the pedometer through baseline week and through week 12 .

The developed pedometer based aerobic walking program was implemented for the study group individually and it included five factors (routine hospital care, educational sessions, pedometer self monitoring, aerobic weekly step count goals and weekly telephone follow up).

- Educational sessions: It was conducted in 4 sessions; each session took about 15 to 45 minutes (according to the activities required in each session and attention span of the patients). They included the following:

- First session: (Overview about AF, management strategies and How to wear pedometer), it was held on first day.

- Second session: (Healthy life style, Aerobic walking and pedometer self monitoring), it was held after 1 week.

- Reinforcement third educa-tional session: (Reinforced education about $\mathrm{AF}$ and management strategies and aerobic walking), it was held after 4 weeks.

- Reinforcement fourth educa-tional session: (Reinforced education about $\mathrm{AF}$ and management strategies and aerobic walking), it was held after 8 weeks.

- Moreover, the instructional booklet was given to each patient in the study group

\section{- Pedometer self monitoring:}

- Pedometer model KFJ-23D was used and it has the following characteristics (accuracy $\pm 5 \%, 3 \mathrm{D}$ digital acceleration sensor, step range 0-99999, calorie range 0-9999.9 kcal, clamped on waistband, 7 days memory and power saving mode).

- Patients were needed to give at least 5 days of step counts per week to obtain a valid estimation of PA levels.

- A valid day of step count was set as more than three hundred steps and that the pedometer worn at least 8 hours per day during awaking hours. Any daily recording lower than three hundred steps was canceled, as this showed that the pedometer wasn't worn and taking this reading might cause inaccurate estimation of daily steps.

- Aerobic weekly step count goals:

- The main aim of the walking program was to raise patients mean daily step-count by three thousands cumulative aerobic steps above their baseline value on 5 days per week or more.

- Patients received their individualized daily step count goals every week to raise gradually by ten percent of baseline steps/d for weeks 2-12.

- Patients were taught to walk at a cadence of 100 step \minute which elicit a moderate, noticeable increase in depth and rate of breathing, while patient can talk with slight effort.

- The second goal is that aerobic walking steps + baseline steps reached from 8000 to 10000 step । day.

- Weekly telephone follow up: patient received weekly telephone call that last for 10 to 15 minutes and its aimed for Recording patient previous 
7 days step count reading, Give the patient feedback about readings, Providing the patient with the new step count goals, Discussing with patient barriers for pedometer use or walking and Motivating patient to increase walking.

Control group receive their routine care only according to outpatient clinic rules which included (taking patient history, physical examination, answering patient queries, Education regarding marevan dose and INR monitoring, give feedback regarding INR results, Written educational materials regarding cardiac patients diet and Give patient his \ her medications.

Table (1): Comparison between the two studied groups of AF patients in relation to demographic characteristics

\begin{tabular}{|c|c|c|c|c|c|}
\hline \multirow{2}{*}{$\begin{array}{r}\text { Items } \\
\text { Sex }\end{array}$} & \multicolumn{2}{|c|}{ Study group } & \multicolumn{2}{|c|}{ Control group } & \multirow{2}{*}{$\begin{array}{c}\text { Significance } \\
\text { test }\end{array}$} \\
\hline & $\mathrm{n}=3$ & $\%$ & $\mathrm{n}=30$ & $\%$ & \\
\hline Male & 16 & 53.3 & 14 & 46.7 & $\chi^{2}=0.267$ \\
\hline \multirow[t]{2}{*}{ Female } & 14 & 46.7 & 16 & 53.3 & P 0.606 \\
\hline & & & & & Age group \\
\hline $50<30-$ & 3 & 10.0 & 5 & 16.7 & $\chi^{2}=0.577$ \\
\hline $50-60$ & 27 & 90.0 & 25 & 83.3 & P 0.448 \\
\hline Mean \pm SD & \multicolumn{2}{|c|}{$56.23 \pm 3.99$} & \multicolumn{2}{|c|}{$55.33 \pm 4.21$} & $\mathrm{t}=0.849, \mathrm{P} 0.399$ \\
\hline & & & & & Social status \\
\hline Single & 3 & 10.0 & 3 & 10.0 & ---------------- \\
\hline \multirow[t]{2}{*}{ Married } & 27 & 90.0 & 27 & 90.0 & ---------- \\
\hline & & & & & Education \\
\hline Illiterate & 14 & 46.7 & 15 & 50.0 & \multirow{4}{*}{$\begin{array}{c}\chi^{2}=1.078 \\
\text { Mont Carlo } \\
\text { P } 1.078\end{array}$} \\
\hline Read / write & 11 & 36.7 & 12 & 40.0 & \\
\hline Secondary & 2 & 6.7 & 2 & 6.7 & \\
\hline \multirow[t]{2}{*}{ University } & 3 & 10.0 & 1 & 3.3 & \\
\hline & & & & & Job status \\
\hline Working & 8 & 26.7 & 9 & 30.0 & $\chi^{2}=0.082$ \\
\hline \multirow[t]{2}{*}{ Not working } & 22 & 73.3 & 21 & 70.0 & P 0.774 \\
\hline & & & & & Residence \\
\hline Rural & 22 & 73.3 & & 80.0 & $\chi^{2}=0.373$ \\
\hline Urban & 8 & 26.7 & & 20.0 & $\mathrm{P} 0.542$ \\
\hline
\end{tabular}

$* \mathrm{p}<0.05$ (significant) the program in study group; step count was assessed every week and pulse rate was assessed during $1^{\text {st }}, 4^{\text {th }}, 8$ th and $12^{\text {th }}$ week while for control group pulse rate and step count were assessed at $1^{\text {st }}$ and $12^{\text {th }}$ week only. Using the study tool II. A comparison was done between pre and post results for both groups to detect the effect of pedometer based aerobic walking program.

\section{3- Results:}

The collected data were statistically analyzed and the results are assorted into 2 main parts which are: Assessment part and effect of executing pedometer based program 
For the socio-demographic characteristics of the study and control groups, no statistical significant differences were found between two groups in relation to all items (table 1).

Regarding associated diseases, Hypertension was more prevalent in control group $(73.3 \%)$ than study group $(53.3 \%)$ with no significant difference $(\chi 2=2.584, \quad \mathrm{P} \quad 0.108) \quad$ while $\mathrm{CAD}$, rheumatic heart disease and valvular disease were more prevalent in study group $(26.7 \%, 40 \%, 53.3)$ than control group $(20 \%, 23.3 \%, 40 \%)$ respectively and About two fifths of both groups had DM with no significant difference $\left(\chi^{2}=0.098, \mathrm{P} 0.754\right)($ table2 $)$

Table (2): Health related data of the study and control groups:

\begin{tabular}{|c|c|c|c|c|c|}
\hline \multirow{2}{*}{$\frac{\text { Items }}{\text { Duration of AF }}$} & \multicolumn{2}{|c|}{ Study group } & \multicolumn{2}{|c|}{ Control group } & \multirow{2}{*}{ Significance test } \\
\hline & $\mathrm{n}=30$ & $\%$ & $\mathrm{n}=30$ & $\%$ & \\
\hline$<1$ year & 3 & 10.0 & 3 & 10.0 & \multirow{3}{*}{$\begin{array}{c}\chi^{2}=2.853 \\
P 0.583\end{array}$} \\
\hline $1-<5$ years & 19 & 63.3 & 16 & 53.3 & \\
\hline \multirow[t]{2}{*}{$\geq 5$ years } & 8 & 26.7 & 11 & 36.7 & \\
\hline & & & & & Type of AF \\
\hline Paroxysmal & 0 & 0.0 & 2 & 6.7 & \multirow{3}{*}{$\begin{array}{c}\chi^{2}=3.156 \mathrm{MC} \\
\text { P } 0.206\end{array}$} \\
\hline Persistent & 0 & 0.0 & 1 & 3.3 & \\
\hline \multirow[t]{2}{*}{ Permanent } & 30 & 100.0 & 27 & 90.0 & \\
\hline & & & & & Symptoms \\
\hline Dyspnea & 24 & 80.0 & 28 & 93.3 & $\chi^{2}=2.308$, P 0.129 \\
\hline Palpitations & 29 & 96.7 & 29 & 96.7 & ------------------------ \\
\hline Chest pain & 10 & 33.3 & 7 & 23.3 & $\chi^{2}=0.739, \mathrm{P} 0.390$ \\
\hline Drowsiness & 24 & 80.0 & 25 & 83.3 & $\chi^{2}=0.111, \mathrm{P} 0.739$ \\
\hline Fatigue & 29 & 96.7 & 29 & 96.7 & -------------------------- \\
\hline \multirow[t]{2}{*}{ Insomnia } & 19 & 63.3 & 20 & 66.7 & $\chi^{2}=0.073, \mathrm{P} 0.787$ \\
\hline & & & & & Associated disease \\
\hline Hypertension & 16 & 53.3 & 22 & 73.3 & $\chi^{2}=2.584$, P 0.108 \\
\hline CAD & 8 & 26.7 & 6 & 20.0 & $\chi^{2}=0.373, \mathrm{P} 0.542$ \\
\hline $\mathrm{Rh}$ heart disease & 12 & 40.0 & 7 & 23.3 & $\chi^{2}=1.926, \mathrm{P} 0.165$ \\
\hline Valvular disease & 16 & 53.3 & 12 & 40.0 & $\chi^{2}=1.071, \mathrm{P} 0.301$ \\
\hline Sleep apnea & 2 & 6.7 & 0 & 0.0 & $\chi^{2}=2.069, \mathrm{P} 0.150 \mathrm{MC}$ \\
\hline $\mathrm{DM}$ & 6 & 20.0 & 7 & 23.3 & $\chi^{2}=0.098, \mathrm{P} 0.754$ \\
\hline COPD & 2 & 6.7 & 3 & 10.0 & $\chi^{2}=0.218, \mathrm{P} 0.640 \mathrm{MC}$ \\
\hline Obesity & 4 & 13.3 & 4 & 13.3 & ----------------------------- \\
\hline Stroke & 2 & 6.7 & 3 & 13.3 & $\chi^{2}=0.218, \mathrm{P} 0.640 \mathrm{MC}$ \\
\hline
\end{tabular}

There were significant difference between $1^{\text {st }}$ weekly step count and $4^{\text {th }}$ weekly step count, $4^{\text {th }}$ weekly step count and $8^{\text {th }}$ weekly step count, $8^{\text {th }}$ weekly step 
count and $12^{\text {th }}$ weekly step count and $1^{\text {st }}$ weekly step count and $12^{\text {th }}$ weekly step count $(\mathrm{t}=12.944$, P 0.000) with significant increase in mean step count from baseline $(3074.4 \pm 1823.6)$ to $(5888.6 \pm 2696)$ at the end of the study (table3).
At end of study the mean step count for study group was5888.6 \pm 2696.0 with significant difference from base line $(\mathrm{t}=12.944, \mathrm{p} 0.000)$ and for control group was $3208.6 \pm 1873.0$ with no significant difference from baseline $(\mathrm{t}=0.245, \mathrm{p}$ $0.808)$. In addition a significant difference was found at the end of study between both study and control groups regarding mean step count $(\mathrm{t}=4.472, \mathrm{p}$ 0.000) (table 4).

Table (3): Distribution of patients in the study group according to mean weekly step count $(\mathrm{n}=30)$ :

\begin{tabular}{|c|c|c|c|c|}
\hline \multirow{2}{*}{ Weeks } & \multicolumn{3}{|c|}{ Step count $(\mathrm{n}=30)$} & \multirow{2}{*}{ Significance test } \\
\hline & Median \pm range & Mean \pm SD & Mean Change & \\
\hline $1^{\text {st }}$ Week & $2289.0 \pm 5818.0$ & $3074.4 \pm 1823.6$ & & \\
\hline $2^{\text {nd }}$ Week & $2494.0 \pm 5774.0$ & $3258.0 \pm 1844.2$ & & \\
\hline $3^{\text {rd }}$ Week & $2787.0 \pm 6227.0$ & $3410.9 \pm 1920.5$ & & \\
\hline $4^{\text {th }}$ Week & $2935.5 \pm 6231.0$ & $3689.2 \pm 2011.0$ & & \\
\hline $1^{\text {st }} \alpha 4^{\text {th }}$ week & & & $614.73 \pm 596.47$ & $\mathrm{t}=4.645, \mathrm{P} 0.000^{*}$ \\
\hline $5^{\text {th }}$ Week & $3365.5 \pm 6546.0$ & $4016.2 \pm 2126.3$ & & \\
\hline $6^{\text {th }}$ Week & $3521.0 \pm 6870.0$ & $4150.1 \pm 2149.4$ & & \\
\hline $7^{\text {th }}$ Week & $3751.0 \pm 7664.0$ & $4435.5 \pm 2307.7$ & & \\
\hline $8^{\text {th }}$ Week & $4215.5 \pm 6936.0$ & $4623.9 \pm 2157.6$ & & \\
\hline $4^{\text {th }} \alpha 8^{\text {th }}$ week & & & $934.8 \pm 765$ & $\mathrm{t}=6.693, \mathrm{P} 0.000 *$ \\
\hline $9^{\text {th }}$ Week & $4564.0 \pm 7713.0$ & $4785.3 \pm 2185.8$ & & \\
\hline $10^{\text {th }}$ Week & $4804.5 \pm 7744.0$ & $5120.3 \pm 2301.7$ & & \\
\hline $11^{\text {th }}$ Week & $4823.5 \pm 7849.0$ & $5442.1 \pm 2513.3$ & & \\
\hline $12^{\text {th }}$ Week & $5195.0 \pm 8662.0$ & $5888.6 \pm 2696$ & & \\
\hline $8^{\text {th }} \alpha 12^{\text {th }}$ week & & & $1264.7 \pm 981.8$ & $\mathrm{t}=7.056, \mathrm{P} 0.000^{*}$ \\
\hline $1^{\text {st }} \alpha 12^{\text {th }}$ week & & & $2814.2 \pm 1190.84$ & $\mathrm{t}=12.944, \mathrm{P} 0.000 *$ \\
\hline
\end{tabular}


Table (4): Comparison between the two studied groups of AF patients in relation to mean step count at $1^{\text {st }} \& 12^{\text {th }}$ weeks:

\begin{tabular}{||cccc||}
\hline & $\begin{array}{c}\text { Study group } \\
\mathrm{n}(30)\end{array}$ & $\begin{array}{c}\text { Control group } \\
\mathrm{n}(30)\end{array}$ & \multirow{2}{*}{ Significance test } \\
\cline { 2 - 3 } Week & Mean $\pm \mathrm{SD}$ & Mean $\pm \mathrm{SD}$ & \\
\hline $1^{\text {st }}$ week & $3074.4 \pm 1823.6$ & $3221.7 \pm 1857.4$ & $\mathrm{t}=0.310, \mathrm{p} 0.758$ \\
\hline $12^{\text {th }}$ week & $5888.6 \pm 2696.0$ & $3208.6 \pm 1873.0$ & $\mathrm{t}=4.472, \mathrm{p} 0.000^{*}$ \\
\hline Paired $\mathrm{t}$ test & $\mathrm{t}=12.944, \mathrm{p} 0.000^{*}$ & $\mathrm{t}=0.245, \mathrm{p} 0.808$ & \\
\hline
\end{tabular}

$* \mathrm{p}<0.05$ (significant)

Table (5): Comparison between the two studied groups of AF patients in relation to step count levels at 1 st \& 12 th week:

\begin{tabular}{|c|c|c|c|c|c|c|c|c|c|c|c|}
\hline \multirow{3}{*}{ Week } & \multirow{3}{*}{ Step } & \multirow{2}{*}{\multicolumn{2}{|c|}{$\begin{array}{c}\begin{array}{c}\text { Sedentary } \\
\text { basal basal }\end{array} \\
<2500\end{array}$}} & \multirow{2}{*}{\multicolumn{2}{|c|}{$\begin{array}{c}\begin{array}{c}\text { Sedentary } \\
\text { limited }\end{array} \\
2500-4999\end{array}$}} & \multirow[t]{3}{*}{$\begin{array}{c}\text { Total } \\
\text { sedentary }\end{array}$} & \multirow{2}{*}{\multicolumn{2}{|c|}{$\begin{array}{c}\text { Low active } \\
5000-7499\end{array}$}} & \multirow{2}{*}{\multicolumn{2}{|c|}{$\begin{array}{l}\text { Active } \\
\geq 7500\end{array}$}} & \multirow{3}{*}{$\begin{array}{c}\text { Significance } \\
\text { test }\end{array}$} \\
\hline & & & & & & & & & & & \\
\hline & & $\mathrm{n}$ & $\%$ & $\mathrm{n}$ & $\%$ & & $\mathrm{n}$ & $\%$ & $\mathrm{n}$ & $\%$ & \\
\hline \multicolumn{12}{|c|}{$1^{\text {st }}$ Week } \\
\hline & $\begin{array}{l}\text { Study } \\
(\mathrm{n}=30)\end{array}$ & 17 & 56.7 & 7 & 23.3 & 80 & 6 & 20.0 & 0 & 0.0 & \multirow{2}{*}{$\begin{array}{c}\chi^{2}=0.107 \\
\text { P0.948 }\end{array}$} \\
\hline & $\begin{array}{c}\text { Control } \\
(\mathrm{n}=30)\end{array}$ & 16 & 53.3 & 7 & 23.3 & 76.6 & 7 & 23.0 & 0 & 0.0 & \\
\hline \multicolumn{12}{|c|}{$12^{\text {th }}$ Week } \\
\hline & $\begin{array}{l}\text { Study } \\
(\mathrm{n}=30)\end{array}$ & 4 & 13.3 & 9 & 30.0 & 43.3 & 5 & 16.7 & 12 & 40.0 & \multirow{2}{*}{$\begin{array}{c}\chi^{2}=18.761 \\
\text { P } 0.000^{*}\end{array}$} \\
\hline & $\begin{array}{c}\text { Control } \\
(\mathrm{n}=30)\end{array}$ & 15 & 50.0 & 8 & 26.7 & 76.7 & 7 & 23.3 & 0 & 0 & \\
\hline
\end{tabular}

$* \mathrm{p}<0.05$ (significant)

At the end of study (76.7\%)of control group were in sedentary level while $40.0 \%$ of study group were in active level with statistically significant difference between both groups $\left(\chi^{2}=18.761, \mathrm{P} 0.000\right)($ table5).

Table (6): Comparison of the two studied groups of AF patient in relation to mean score of pulse rate at rest before and after intervention:

\begin{tabular}{|cccc|}
\hline \multirow{2}{*}{ Week } & Study group & Control group & \multirow{2}{*}{ Significance test } \\
\cline { 2 - 3 } & Mean \pm SD & Mean \pm SD & \\
\hline $\mathbf{1}^{\text {st }}$ week & $75.20 \pm 12.22$ & $74.8 \pm 10.79$ & $\mathrm{t}=0.134, \mathrm{p} 0.894$ \\
\hline $\mathbf{4}^{\text {th }}$ week & $74.23 \pm 10.58$ & & \\
\hline $\mathbf{8}^{\text {th }}$ week & $73.16 \pm 10.50$ & & \\
\hline $\mathbf{1 2}^{\text {th }}$ week & $71.27 \pm 8.79$ & $75.50 \pm 10.04$ & $\mathrm{t}=1.737, \mathrm{p} 0.08$ \\
\hline $\begin{array}{c}\text { Paired } \text { t test } \mathbf{1}^{\text {st }} \boldsymbol{\alpha} \\
\mathbf{1 2}^{\text {th }} \text { week }\end{array}$ & $\mathrm{t}=3.179$ & $\mathrm{t}=0.760$ & \\
\hline
\end{tabular}

$\mathrm{p}<0.05$ (significant) 
The mean score of pulse rate At 12th week for study group was $71.27 \pm$ 8.79 with significant decrease in comparison to baseline $(\mathrm{t}=3.179, \mathrm{p} 0.004)$ , while for control group the mean score of pulse rate were $75.50 \pm 10.04$ with no significant difference in comparison with baseline $(\mathrm{t}=0.760, \mathrm{p} 0.453)$ and with no statistically significant difference was found between two groups $(t=1.737, p$ 0.08) (table 6).

\section{4- Discussion:}

$\mathrm{AF}$ is a chronic condition that significantly affects patient's exercise capacity and activities of daily living due to its symptoms, including dyspnea , palpitations, exercise intolerance, and immediate fatigue. Patients with permanent AF may obviate activities requiring exertion, such as work/housework, go up stairs, exercise, and sexual activity, fearing their palpitations will be triggered ${ }^{(24)}$.

Health care providers are encouraged to promote exercise, among other lifestyle modifications, to their patients in an attempt to dampen the burden of AF and its associated symptoms and to decrease the heavy reliance on pharmaceutical and interventional strategies for arrhythmia management ${ }^{(25)}$.

Current reviews show that interventions that emphasize monitoring of self, goal establishment, recognizing hindrances to change and preventing relapse are more probably to produce positive effects for patients ${ }^{(26-27)}$. The pedometers utilization for self-monitoring has been shown to be linked with raised levels of PA in patients with cardiac diseases but scant data is available regarding $\mathrm{AF}$ patients ${ }^{(28)}$. In this study we aim to increase walking steps of $\mathrm{AF}$ patients by 3000 aerobic step above baseline value using pedometer self monitoring and setting step count goals.
Discussion of the study results will be presented under the following: The sociodemographic and health related data of the present study showed that, regarding age of study and control group, most patients' age ranged from $50-60$ years old, with mean age (56) and (55) years respectively. The results of the study support the fact that the incidence of atrial fibrillation increases with age ${ }^{(29)}$. In addition The Gulf survey of Characteristics of the Arab Middle East Patients with Atrial Fibrillation supports the previous findings where mean age of patients with $\mathrm{AF}$ was 57 years ${ }^{(30)}$.

In relation to residence about three quarters of study group and four fifths of control group lived in rural areas. This is in agreement with other studies conducted at Egypt and china in which AF was more prevalent in rural than urban areas $(16,31)$. This may be due to higher prevalence of rural populations in Egypt $(57 \%)^{(32)}$, poor socioeconomic status and poor health care services quality in rural areas in developing countries that leads to higher prevalence of rheumatic heart disease (RHD) which is more predominant among young females than males. It mainly cause valvular heart disease - particularly mitral stenosis which is the main cause of arrhythmia ${ }^{(33)}$. In the present study, for study group females, valvular heart disease and RHD account for $(46.7 \%$, $53.3 \%, 40 \%)$ respectively and in control group they account for $(53.3 \%, 40 \%$, $23.3 \%$ ) respectively.

Most patients of both study and control groups had permanent AF. This result is in agreement with RE-LY AF registry which surveyed 46 countries and Egypt was one of them and reported that in Africa and the Middle East about four fifths and three quarters, respectively, of the patients had permanent AF and in contrast Western Europe had equal distribution between AF types (34). This may be due to that in 
developing countries as noted before RHD had high prevalence and it is always discovered late owing to inadequate health care staff in rural regions and this end with late detection of noncompliant small heart with permanent $\mathrm{AF}$ where by any ways restoring or maintaining sinus rhythm is not the choice ${ }^{(35)}$.

The AF is associated with a variety of cardiovascular and non cardiovascular conditions. In the present study the most concomitant conditions for both groups were in order hypertension, valvular disease, RHD, CAD, and Diabetes Mellitus (DM). This is in accordance with two studies; the gulf survey which included 6 Middle East countries and another international study that included 26 countries and Egypt is one of them, they reported that hypertension was the most common concomitant condition in AF patients $(30,36)$. In contrast another study conducted at India reported that RHD was the most common concomitant condition in AF patient ${ }^{(37)}$.

Concerning step count, this study revealed that both study and control groups mean step count at baseline was at sedentary level $(3074.4 \pm 1823.6,3221.7 \pm$ 1857.4) respectively, with four fifths of both groups were in sedentary category and no patients were in active category.

This is in accordance with a study conducted at USA among cardiac rehabilitation patients which reported that baseline mean step count for both groups was at sedentary level $(3.763,3.175)$ respectively, with more than four fifths of participants were in sedentary category ${ }^{(38)}$. Another study conducted at USA reported that baseline mean step count during non cardiac rehabilitation days for both groups was at sedentary level $(4.129,4.143)$ respectively ${ }^{(39)}$. In addition other two studies conducted at Brazil and USA reported that about three quarters and three fifths of cardiac patients respectively were at sedentary level ${ }^{(40-41)}$.
At $4^{\text {th }}$ week study group patients had a significant increase in mean step count but with no significant change in step count levels from baseline as still no patients were in active category, while at $8^{\text {th }}$ and $12^{\text {th }}$ week there was significant change in step count levels from baseline with $6.7 \%$ and two fifths respectively were in active category. This means that the major change in study group step count levels were at middle and end of study.

This finding is in contrast to a study conducted at Northern Ireland on cardiac rehabilitation patients which reported that the highest rise in steps was in the $1^{\text {st }}$ week of study ${ }^{(42)}$. Another study conducted at Tennessee reported that greatest increase in mean step count occurred in first 4 weeks and then followed by plateau at middle weeks of study ${ }^{(38)}$. This may be due to that all our patients didn't have any idea about pedometer device and how to use it, so it take time to encourage patients to use pedometer and make it part of their usual daily routine, but in western countries pedometer is not new for patients and they only need a program to motivate and encourage walking, it is available on their mobiles and easy to use for them.

At week 12 this study shows that study group increased their mean step count significantly more than control group (5888.6 $\pm 2696.0 \quad$ VS $3208.6 \pm 1873.0)$ with about two fifths of study group and no patients in control group were in active category and with change in mean step count of study group from sedentary level to low active level.

At least a rise of 2,500 step/d is linked with health improvements for patients with long lasting diseases (15) which the study group patients achieved for their mean daily step count (2814). These findings support study hypothesis that patients who practice 12 weeks of pedometer based aerobic walking program 
EFFECT OF PEDOMETER BASED AEROBIC WALKING etc...

will have significant improvement in their step count.

This also is in accordance with cupples etal, ${ }^{(42)}$ who reported a mean increase of 2742 steps / day of cardiac patients using pedometers and receive step count goals than control patients. In addition Shipe ${ }^{(38)}$ reported change in mean step count from sedentary level to low active level with mean increase of 2635 step / day. Another study conducted at Brazil reported increase in mean step count among hypertensive patients by 2095 step / day (40). Another study conducted at Australia among cardiac patients reported significant improvement in walking time in pedometer based telephone study group than control group $^{(43)}$.

In contrast kaminsky etal (39) reported non significantly higher mean step count for pedometer feedback group than control group during non cardiac rehabilitation days and this may be due to short time of study, only 8 weeks and there were no telephone feedback. Another study conducted among patients with vascular disease reported non significant increase in mean step count in participants who receive pedometer and this may be due to that participants in this study didn't receive step count goals to accomplish ${ }^{(44)}$.

Rate control is the $1^{\text {st }}$-line therapy to all patients with AF. In persistent and permanent AF cases, rate control is used constantly. In paroxysmal AF patients, the rate control aims to limit ventricular response throughout episode of AF. Current guidelines recommended strict rate control aiming at a resting heart rate between 60-80 bpm and 90-115 bpm throughout moderate exercise ${ }^{(45)}$.

Regarding resting heart rate, this study showed that after intervention the resting heart rate of study group patients dropped significantly by 4 beats / minute while for control group no significant changes were observed. In addition no statistically significant difference was found between both groups.

This is in accordance with study conducted at Norway among AF patients which reported that after 12 weeks, patients in exercise group had a significant reduction in resting heart rate by $(3 \mathrm{~b} / \mathrm{m})$ with no statistically significant difference compared with control group ${ }^{(10)}$. Another study conducted at India among diabetic patients reported that patients practicing pedometer based aerobic walking program had significant decrease in RHR by ( 8 $\mathrm{b} / \mathrm{m}$ ) with non significant change in control group and with non significant difference between both groups (46). Another study conducted at Canada among patients with permanent AF reported decrease in heart rate by 8 beats $\backslash$ minute from $(83$ to $75 \mathrm{~b} \backslash \mathrm{m}$ ) in patients practicing high intensity exercises for 10 weeks ${ }^{(47)}$. Other two studies conducted at Denmark reported significant decrease in resting heart rate by $(8 \mathrm{~b} / \mathrm{m}, 9 \mathrm{~b} / \mathrm{m})$ respectively in patients receive aerobic exercise training VS control group with non significant difference between both groups ${ }^{(8,9)}$.

\section{5- Conclusion:}

Findings of this study revealed that study group patients subjected to pedometer based aerobic walking program showed significant improvement in daily step count and resting heart rate than those not subjected to the program.

\section{6-Recommendation}

Based on the results of the present study the following recommendations are suggested:-

- A developed self monitoring program for PA should be available at each cardiac outpatient clinic to improve exercise adherence.

- Education regarding AF disease, anticoagulation control, detection and recurrence, self monitoring and aerobic walking should be routinely and consistently provided to all AF patients prior to discharge from 
hospital and during follow up at outpatient clinics to improve patient understanding and motivation to exercise.

- Both literate and illiterate people in need for tailored Information Education \& Communication materials on AF symptom, risk factors, complication, warfarin treatment and healthy lifestyle including aerobic exercises for $\mathrm{AF}$ patient should be developed and disseminated during patients waiting time in outpatient clinic.

- A designed audiovisual material should be showed during patient waiting that show aerobic exercises that AF patient should practice.

For further research:

- Replication of the study using a larger number of sample and various settings in Egypt and with the latest pedometer models for aerobic walking program self monitoring to confirm these findings.

- More studies are needed to assess barriers for AF patient's adherence to exercise.

- Investigate the effect of pedometer based aerobic walking program on muscle strength, body composition, ejection friction and pulse rate during exercise.

\section{7- Conflict of interest:}

The authors declare that they have no conflict of interests.

\section{8-Acknowledgments:}

Thanks to all patients who took part in the study, to all the nurses and other healthcare staff on cardiovascular department.

\section{9-Funding:}

Partial funding sources were provided from Mansoura University.

\section{0- References:}

1. Wong CX, Brooks AG, Leong DP, Roberts-Thomson KC, Sanders P. (2012): The increasing burden of atrial fibrillation compared with heart failure and myocardial infarction: a 15-year study of all hospitalizations in Australia. Arch Intern Med ; 172:739741.

2. Wong CX, Lau DH, Sanders P. (2014): Atrial fibrillation epidemic and hospitalizations: how to turn the rising tide? Circulation ; 129:2361-2363.

3. Patel NJ, Deshmukh A, Pant S, Singh V, Patel N, Arora S, Shah N, Chothani A, Savani GT, Mehta K, Parikh V, Rathod A, Badheka AO, Lafferty J, Kowalski M, Mehta JL, Mitrani RD, Viles-Gonzalez JF, Paydak H. Contemporary trends of hospitalization for atrial fibrillation in the United States, 2000 through 2010: implications for healthcare planning. Circulation. 2014; 129:2371-2379.

4. Zoni-Berisso M, Lercari F, Carazza T, Domenicucci S. (2014): Epidemiology of atrial fibrillation: European perspective . Clin Epidemiol 2014;6:213-220.

5. Goren A, Liu X, Gupta S, et al. Quality of life, activity impairment, and healthcare resource utilization associated with atrial fibrillation in the US National Health and Wellness Survey. PLoS One 2013; 8:e71264.

6. World Health Organization (2010): Global recommendations on physical activity for health. Geneva: http://www.who.int/

dietphysicalactivity/factsheet_recomm endations/en/, 2010 ( accessed 11.01.17) 
EFFECT OF PEDOMETER BASED AEROBIC WALKING etc...

7. Lowres N, Neubeck L, Freedman SB, Briffa T, Bauman A, Redfern J. Lifestyle risk reduction interventions in atrial fibrillation: a systematic review. Eur. J. Prev. Cardiol. 2012; 19: 1091-1100. [PubMed].

8. Osbak, P. S., Mourier, M., Kjaer, A., Henriksen, J. H., Kofoed, K. F., \& Jensen, G. B. (2011). A randomized study of the effects of exercise training on patients with atrial fibrillation. American Heart Journal, 162(6), 1080-1087. https://doi.org/ 10.1016/ j.ahj. 2011.09 .013$.

9. Osbak, P. S., Mourier, M., Henriksen, J. H., Kofoed, K. F., \& Jensen, G. B. (2012). Effect of physical exercise training on muscle strength and body composition, and their association with functional capacity and quality of life in Patients with Atrial fibrillation: A Randomized controlled trial. Journal of Rehabilitation Medicine, 44(11), 975979. https://doi.org/ 10. 2340/ 16501977-1039.

10. Malmo, V., Nes, B. M., Amundsen, B. H., Tjonna, A. E., Stoylen, A., Rossvoll, O., Loennechen, J. P. (2016). Aerobic interval training reduces the burden of Atrial fibrillation in the short term: A randomized trial. Circulation, 133(5), 466-473. https:// doi.org/10.1161

CIRCULATIONAHA.115.018220.

11. Giacomantonio NB, Bredin SSD, Foulds HJA, Warburton DER. A Systematic Review of the Health Benefits of Exercise Rehabilitation in Persons Living With Atrial Fibrillation. Can. J. Cardiol. 2013;29:483-91. doi: 10.1016/j.cjca.2012.07.003 [PubM ed].

12. Bhella PS, Hastings JL, Fujimoto N, Shibata S, Carrick-Ranson G, Palmer MD, Boyd KN, Adams-Huet B, Levine BD. (2014): Impact of lifelong exercise "dose" on left ventricular compliance and distensibility. J Am Coll Cardiol. 64:1257-1266.

13. Glazer NL, Lyass A, EsligerDW, Blease SJ, Freedson PS, Massaro JM, Murabito JM, Vasan RS. Sustained and shorter bouts of physical activity are related to cardiovascular health. Med Sci Sports Exerc 2013;45: 109-15.

14. Garber CE, Blissmer B, Deschenes MR, Franklin BA, Lamonte MJ, Lee IM, Nieman DC, Swain DP. American College of Sports Medicine position stand. Quantity and quality of exercise for developing and maintaining cardio-respiratory, musculo- skeletal, and neuromotor fitness in apparently healthy adults: guidance for prescribing exercise. Med Sci Sports Exerc 2011;43: 1334-1359.

15. Tudor-Locke C, Craig C, Brown W, Clemes S, Cocker $\mathrm{K}$, Corti $\mathrm{B}$, Hatano $\mathbf{Y}$, Inoue $\mathrm{S}$, Matsudo $\mathrm{S}$, Mutrie N, Oppert J, Rowe D, Schmidt M, Schofield G, Spence J, Teixeira $P$, Tully $M$ and Blair $S$. (2011): How Many Steps / Day are Enough? for Adults. International Journal of Behavioral Nutrition and Physical Activity, 8(1), 79. doi:10.1186/1479-5868-8-79.

16. Elzeky M. (2014).Assessment of knowledge and self management behaviors among patients with chronic 
atrial fibrillation. Unpublished Master thesis. Faculty of Nursing, Mansoura university.

17. Abd- Elmawla RA. (2010): assess compliance to therapeutic regimen for patients with angina pectoris. Unpublished Master thesis .Faculty of nursing, Mansoura university.

18. Abd El-Mawla RA. (2014): Effect of cardiac rehabilitation program on health behavior and physiological risk parameters for patients with coronary heart disease. Unpublished Doctoral thesis .Faculty of Nursing, Mansoura University.

19. Ahmed FAHM. (2015).Effect of health education guidelines to prevent complications associated therapeutic cardiac catheterization at specialized medical hospital of Mansoura. Unpublished Master thesis .Faculty of Nursing, Mansoura University.

20. Artinian NT, et al.(2010): Interventions to promote physical activity and dietary lifestyle changes for cardiovascular risk factor reduction in adults: a scientific statement from the American Heart Association. Circulation; 122(4):406-41.

21. Rowe-Roberts D, et al. (2014): Preliminary results from a study of the impact of digital activity trackers on health risk status. Stud Health Technol Inform ; 204:143-8.

22. Rippe JM. (2012): Encyclopedia of Lifestyle Medicine \& Health. . volume 1.Sage, USA: 331-334.ISBN 978-14129-5023-7.

23. DSS research. Available at: https:// www.Dss research.com/knowledge center/ tool kit calculators. Aspx. accessed on Jan , 2017.
24. Altiok, M., Yilmaz, M., \& RencüsoGullari , I. (2015). Living with Atrial Fibrillation: An Analysis of Patients' Perspectives. Asian Nursing Research, 9(4), 305-311. https://doi.org/ 10.1016/ j.anr. 2015. 10.001 .

25. Elliott AD, Mahajan R, Pathak RK, et al. (2016): Exercise training and atrial fibrillation: further evidence for the importance of lifestyle change. Circulation; 133(5):457-459.

26. Chase JA (2011) Systematic review of physical activity intervention studies after cardiac rehabilitation. J Cardiovasc Nurs 26: 351-358.

27. Ferrier S, Blanchard CM, Vallis M, Giacomantonio N (2011) Behavioural interventions to increase the physical activity of cardiac patients: a review. Eur J Cardiovasc Prev Rehabil 18: 1532.

28. Pinto BM, Goldstein MG, Papandonatos GD, Farrell N, Tilkemeier P, et al. (2011) Maintenance of exercise after phase II cardiac rehabilitation: a randomized controlled trial. Am J Prev Med 41: 274-283.

29. Lip GY, Tse HF, Lane DA. Atrial fibrillation. Lancet. 2012; 379:648661. DOI:10.1016/ S 0140 6736(11)61514-6.

30. Zubaid, M., Rashed, W. A., Alsheikh-Ali, A. A., AlMahmeed, W., Shehab, A., Sulaiman, K., Amin, H. (2011). Gulf survey of atrial fibrillation events (Gulf SAFE) design and baseline characteristics of patients with atrial fibrillation in the arab middle East. Circulation: Cardiovascular Quality and Outcomes, 4(4), 477-482. 
EFFECT OF PEDOMETER BASED AEROBIC WALKING etc...

https://doi.org/ 10.1161/ CIRC OUTCOMES.110.959700.

31. Chei CL, Raman P, Ching CK, et al. Prevalence and risk factors of atrial fibrillation in chinese elderly: results from the Chinese longitudinal healthy longevity survey. Chin Med J (Engl) 2015; 128:24262432.

32. World bank statistics, 2015.retrieved from http://data. worldbank.org /indicator/ SP. RUR. TOTL. ZS accessed at junuary 2017.

33. Zuhlke, L., Engel, M. E., Karthikeyan, G., Rangarajan, S., Mackie, P., Cupido, B., Mayosi, B. M. (2015). Characteristics, complications, and gaps in evidence-based interventions in rheumatic heart disease: The Global Rheumatic Heart Disease Registry (the REMEDY study). European Heart Journal, 36(18), 1115-1122.

34. Oldgren, J., Healey, J. S., Ezekowitz, M., Commerford, P., Avezum, A., Pais, P., Yusuf, S. (2014). Variations in cause and management of atrial fibrillation in a prospective registry of 15400 emergency department patients in 46 countries: The RE-LY atrial fibrillation registry. Circulation 2014;129:1568-1576.

35. Kar, S. K. (2016). Atrial Fibrillation: Paradigm Shift in Concept Leading to Change in Treatment Strategies in the Developing World, 6(3), 6-7.

36. Chiang, C.-E. et al. (2012): Distribution and risk profile of paroxysmal, persistent, and permanent atrial fibrillation in routine clinical practice: insight from the real-life global survey evaluating patients with atrial fibrillation international registry.
Circ. Arrhythm. Electrophysiol. 5, 632-639.

37. Bhardwaj ， R. (2012): Atrial fibrillation in a tertiary care institute-a prospective study. Indian Heart J. 64, 476-478.

38. Shipe, M. (2009). The Effects of a Pedometer Intervention on The Physical Activity Patterns of Cardiac Rehabilitation Participants. University of Tennessee. published doctorate thesis.

39. Kaminsky, L. A., Jones, J., Riggin, K., \& Strath, S. J. (2013). A pedometer-based physical activity intervention for patients entering a maintenance cardiac rehabilitation program: a pilot study. Cardiovasc Diagn Ther, 3(2), 73-79. https://doi.org /10.3978/ j.issn.22233652.2013.03.03.

40. Paula, T. P., Viana, L. V, Neto, A. T. Z., Leitão, C. B., Gross, J. L., \& Azevedo, M. J. (2015). Effects of the DASH Diet and Walking on Blood Pressure in Patients With Type 2 Diabetes and Uncontrolled Hypertension: A Randomized Controlled Trial. Journal of Clinical Hypertension (Greenwich, Conn.), 17(11), 895-902. https://doi.org/ $10.1111 /$ jch. 12597 ,

41. Savage, P. D., \& Ades, P. a. (2008). Pedometer step counts predict cardiac risk factors at entry to cardiac rehabilitation. Journal of Cardiopulmonary Rehabilitation and Prevention, 28, 370-377-379. https://doi.org/10.1097/HCR.0b013e31 $818 \mathrm{c} 3 \mathrm{~b} 6 \mathrm{~d}$.

42. Cupples M, Dean A, Tully MA, Taggart M, McCorkell G, O'Neill S 
Mohamed Elsayed Elzeky et. al.

and Coates V. (2013): Using

Pedometer Step-Count Goals to

Promote Physical Activity in Cardiac

Rehabilitation: A Feasibility Study of a

Controlled Trial. Int J Phys Med

Rehabil 1(7): 1-5. doi:10.4172/23299096.1000157.

43. Furber, S., Butler, L., Phongsavan, P., Mark, A., \& Bauman, A. (2010). Randomised controlled trial of a pedometer-based telephone intervention to increase physical activity among cardiac patients not attending cardiac rehabilitation. Patient Education and Counseling, 80(2), 212218.

https://doi.org/10.1016/j.pec.2009.11.0 12

44. Betz, H. H., Myers, J., Jaffe, A., Smith, K., \& Dalman, R. (2014). Influence of pedometers on habitual physical activity patterns in patients with vascular disease. Healthy Aging Research | www.har-journal.com, 3:16. doi.org/10.12715/har.

45. Cowan C, Campbell J, Cheong VL, Chung G, Fay M, Fitzmaurice D, Lip G, Mann C, Mills N, Porter E, Power S, Schilling R, Schiff R, Ashe J,
Avital L, Jones C, Naqvi Z, Parnham J, Pollit V, Hunter S, Rose P, (2014):Atrial fibrillation: the management of atrial fibrillation Clinical guideline, Methods, evidence and recommendations .National Clinical Guideline Centre, available at: // publications. nice.org.uk/atrialfibrillation-cg36.

46. Shenoy, S., Guglani, R., \& Sandhu, J. S. (2010). Effectiveness of an aerobic walking program using heart rate monitor and pedometer on the parameters of diabetes control in Asian Indians with type 2 diabetes. Primary Care Diabetes, 4(1), 41-45. https://doi.org/ 10.1016/j. pcd. 2009.10.004.

47. Reed, J. L., Nery, P. B., Birnie, D. H., Tulloch, H. E., \& Pipe, A. L. (2015). High-intensity interval training improves cardiovascular health, exercise capacity, and quality of life in permanent atrial fibrillation: a case study. Applied Physiology, Nutrition, and Metabolism, 40(12), 1321-1323. https://doi.org/10.1139/apnm-20150356 [doi] 